\title{
Cryopreservation of Canine Ovaries by Vitrification
}

\author{
Takako ISHIJIMA ${ }^{1)}$, Yoshiyasu KOBAYASHI ${ }^{1)}$, Dong-Soo LEE'), \\ Yoshiko Yanagimoto UETA ${ }^{1}$, , Motozumi MATSUI'), Jung-Youn LEE'), \\ Yoshinori SUWA ${ }^{2)}$, Kazuro MIYAHARA ${ }^{1)}$ and Hiroshi SUZUKI ${ }^{1,3)}$
}

1) Obihiro University of Agriculture and Veterinary Medicine, Inada-cho, Obihiro, Hokkaido 080-8555, ${ }^{2)}$ Hokkaido Guide Dog Association, Sapporo, and ${ }^{3)}$ Department of Developmental and Medical Technology, Graduate School of Medicine, The University of Tokyo, Tokyo, Japan

\begin{abstract}
The cryopreservation of ovarian tissues is a technology with significant potential for the preservation of the genetic resource materials of working dogs, including guide dogs for the blind. However, no attempt has been reported on cryopreservation of the canine ovary. Thus, we evaluated a vitrification method for cryopreservation of canine ovaries and determined the potential functionality of vitrified-warmed canine ovaries by means of transplantation into non-obese diabeticsevere combined immunodeficiency (NOD-SCID) mice. All ovarian tissues cryopreserved by vitrification were morphologically normal in terms of histology. Cryopreserved ovaries were transplanted into the ovarian bursa of the NOD-SCID mice, and the xenografts were recovered from 23 of 23 mice (100\%) 4 weeks after the operation. The transplanted canine tissue was tightly adhered to the mouse ovary. Although antral follicle formation did not occur after grafting, proliferating cell nuclear antigen immunoreactivity was detectable in many of the granulosa cells in the primary follicles of the grafts. These results indicate that cryopreservation of the canine ovary by vitrification appears to have the potential to restore endocrine function and ovulation potential.

Key words: Canine, Ovary transfer, Transplantation, Vitrification, Xenograft
\end{abstract}

(J. Reprod. Dev. 52: 293-299, 2006)

$\mathbf{I}^{\mathrm{n}}$ n Japan, current figures indicate that approximately 950 dogs are actively engaged in guiding blind people. However, this number is low in light of the estimated demand, which ranges between 4800-7800, including latent need. Annually, the Society for the Blind is provided with about 120 newly trained dogs. Considering, however, that at present about 90-100 guide dogs are retired due to ageing every year, the actual increase is only 20-30 animals per year. Thus, this rate is far from meeting the demand for dogs for the blind. One of the most contributing features of the

Accepted for publication: November 30, 2005

Published online: December 28, 2005

Correspondence: H. Suzuki (e-mail: hisuzuki@obihiro.ac.jp) lack of guide dogs is the spaying of both female and males in advance of the beginning of training. Thus, even if the newly trained animals were to distinguish themselves as superior guide dogs, unfortunately, they could never produce offspring, which may be especially fit for such training. Generally, the males and females used for breeding are not evaluated for their potential to serve as guide dogs. These distinctly different systems applied to the raising and training of dogs for the blind considerably influences the efficiency of establishment of the replenishing colony. In addition, the Labrador retriever breed, which is extensively used as a guide dog for the blind in Japan, is a high frequency carrier of certain severe 
genetic defects, manifesting such symptoms as hip and elbow joint dysplasia, as well as cataracts and retinopathy, which are undesirable for an animal with a role in guiding the blind. Consequently, the percentages of successful guide dogs have ranged from $30-40 \%$ each year in Japan. This current situation urgently requires countermeasures to meet and sustain the supply of high quality guide dogs in Japan. If excised ovaries of candidate guide dogs could be cryopreserved and then transferred as a graft once the animals have been determined to be superior dogs, their germ cells might be transmitted to the next generation. This system would help make it possible to overcome one of the problems described above. Thus, we have proposed the establishment of a genetic resource bank for breeding guide dogs for the blind, which would also include the genetic material of other working dogs. The cryopreservation of ovarian tissues is potentially a significant technology for the preservation of the genetic resources of working dogs as well as other target animals. However, no attempt cryopreservation of the canine ovary has yet appeared in the literature. In the mouse, successful ovarian cryopreservation by a vitrification method has been reported [1, 2], although it is generally considered that application of this method to other ovarian tissues is difficult. In humans, cryopreservation of the ovary has been employed in clinical medicine to restore the fecundity of young women suffering from infertility and premature menopause due to iatrogenic loss of ovarian function resulting from chemotherapy and/or radiation therapy for malignant neoplasms. The establishment of human ovarian tissue banking for patients has been proposed [3], and recently, a live birth after orthotopic transplantation of cryopreserved ovarian tissues in humans has been reported [4, 5], although the possibility that the eggs were derived from the native ovary could not be completely ruled out. On the other hand, the potential technical simplicity of vitrification could revolutionize cryopreservation of the ovary and contribute to the establishment of an ovarian bank for guide dogs for the blind, as well as for clinical medicine in humans.

The objectives of our study were 1) to evaluate a simple vitrification method for cryopreservation of canine ovaries and 2) to determine the potential of the vitrified-warmed canine ovary by means of transplantation to non-obese diabetic-severe combined immunodeficiency (NOD-SCID) mice.

\section{Materials and Methods}

\section{Vitrification of the canine ovary}

Canine ovaries were collected from bitches undergoing routine ovariohystrectomy (aged 5-9 months, $n=10$ ). The ovaries were transported to the laboratory in a jar containing sterile saline at $4 \mathrm{C}$. The fresh canine ovaries were dissected in a $10 \mathrm{~cm}$ diameter Petri dish half-filled with HTF medium [6] to separate the cortex and medulla. The cortex was further sectioned into $1 \mathrm{~mm} \times 1 \mathrm{~mm} \times 1 \mathrm{~mm}, 3$ $\mathrm{mm} \times 3 \mathrm{~mm} \times 3 \mathrm{~mm}$, or $5 \mathrm{~mm} \times 5 \mathrm{~mm} \times 5 \mathrm{~mm}$ slices, and maintained at $37 \mathrm{C}$ in HTF medium. The ovarian slices were pretreated with PBI medium [7] containing $1 \mathrm{M}$ dimethyl sulfoxide (DMSO) at room temperature. The slices were transferred into a 1ml cryotube (Nalge Nunc International, Tokyo, Japan) containing $5 \mu \mathrm{l}$ of $1 \mathrm{M}$ DMSO, which was then placed in ice water for 5 min to allow DMSO to thoroughly bathe the ovaries. Subsequently, $95 \mu \mathrm{l}$ of DAP 213 solution (2 M DMSO, $1 \mathrm{M}$ acetamide, 3 $\mathrm{M}$ propylene glycol) [8], maintained at $0 \mathrm{C}$, was added to each cryotube. After placing the cryotubes in ice water for $5 \mathrm{~min}$, they were plunged directly into liquid nitrogen and stored until use. The samples were taken from the liquid nitrogen and allowed to stand at room temperature for 60 sec, and then diluted with $900 \mu$ of PBI medium (37 C) containing $0.25 \mathrm{M}$ sucrose. The recovered ovaries were transferred to PBI medium, washed 5 times, and transferred to HTF medium; both media were maintained at $0 \mathrm{C}$. The fresh and vitrifiedwarmed ovaries were fixed with $10 \%$ buffered formalin. The fixed tissues were embedded in paraffin wax, sectioned, and stained with hematoxylin and eosin.

\section{Transplantation of ovaries}

Female and male NOD-SCID mice were purchased from a commercial supplier (CLEA Japan, Tokyo, Japan) and were bred in the animal facility of the National Research Center for Protozoan Diseases at Obihiro University of Agriculture and Veterinary Medicine, Obihiro, Japan. All animals were housed in polycarbonate cages and were maintained in a specific pathogenfree environment in light-controlled (lights-on from 
07:00 to 19:00) and air-conditioned rooms (temperature: $24 \pm 1 \mathrm{C}$; humidity: $50 \pm 10 \%$ ). The animals had free access to standard laboratory chow (CE-2; CLEA Japan) and water ad libitum. The vitrified-warmed ovaries were transplanted into 8wk-old female NOD-SCID mice. Recipients were anesthetized with $5 \mathrm{mg} / \mathrm{ml}$ of sodium pentobarbital (Dainippon Pharmaceutical Co., Ltd., Osaka, Japan). Each anesthetized mouse was placed under a dissecting microscope. A single median longitudinal skin incision was made on the lumber portion to expose the subcutaneous tissue over the ovary. A small incision was made on the fascia and muscles immediately above the ovary, thereby exteriorizing the recipient's reproductive tract. A slit was made on the ovarian bursa through the fat tissue to expose the ovary, and both ovaries were removed from the recipient. A small portion (approximately 20-30\%) of the recipient's ovarian tissue was left in situ in order to facilitate regeneration of the blood supply into the grafted tissues. Fresh or vitrified-warmed canine ovaries were inserted into the ovarian bursa on each side. The bursal membrane was then closed, and the reproductive tract was returned to the abdominal cavity. The skin incision was closed with a clip (9$\mathrm{mm}$ auto clip, 427631, Becton Dickinson). The operated mice were placed on a warm plate until sufficient recovery had occurred to allow movement. The mice were then returned to their cages. At 4 weeks after the transplantation, the recipients were sacrificed by cervical dislocation. The ovaries were isolated under a stereomicroscope. Histological examination was performed as described above. In addition, ovarian tissue sections originating from the grafts were randomly selected and evaluated for immunolocalization of proliferating cell nuclear antigen (PCNA) [9]. An anti-PCNA mouse monoclonal antibody (PC-10, prediluted, Nichirei Corp., Tokyo, Japan) was used as the primary antibody. Deparaffinized sections were heated in citrate buffer to enhance antigen retrieval and subjected to the peroxidase-labeled streptavidinbiotin (SAB-PO) method with diaminobenzidine as the chromogen. The reagents used were from a Histfine SAB-PO kit (Nichirei Corp.). Sections were counterstained with hematoxylin.

The animals used in this study were treated under the Guiding Principles for the Care and Use of Research Animals established by the Obihiro
University of Agriculture and Veterinary Medicine.

\section{Results}

After cryopreservation of the canine ovaries by vitrification, as shown in Fig. 1, histological examination revealed that none of the cryopreserved ovarian fragments exhibited structural organ damage. Since there was no difference in the morphology of the vitrifiedwarmed tissues between the different sample volume $\left(1 \mathrm{~mm}^{3}\right.$ to $\left.125 \mathrm{~mm}^{3}\right)$, we utilized the $3 \mathrm{~mm} \times$ $3 \mathrm{~mm} \times 3 \mathrm{~mm}$ fragments for further experiments. All of the 30 frozen-thawed ovarian tissues were morphologically normal on histological examination. Furthermore, there was no difference in the average number of primordial and primary follicles between the vitrified-warmed and fresh ovarian tissues (data not shown). All animals recovered from surgeries and survived the postoperative period. The ovarian grafts were examined 4 weeks after transplantation. On autopsy, the cryopreserved canine xenografts were distinguishable and were recovered in 23 of 23 mice $(100 \%)$. The xenografts were identified in 39 of 46 $(85 \%)$ of the transplanted sites. On the other hand, when fresh canine ovarian tissues were transplanted to the ovarian bursa of NOD-SCID mice, the xenografts were recovered in 3 of 4 (75\%) recipients. The transplanted canine tissue tightly adhered to the mouse ovaries but not to the bursal membrane (Figs. 2-C and -D). The presence of red blood cells was observed in the parenchyma of canine as well as mouse ovaries, indicating reintegration of the bloodstream in the canine ovary into the ovarian bursa of the host animal. No adhesive inflammation was seen. Although antral follicle formation did not take place within 4 weeks postgrafting as shown in Figs. 3-B and -D, PCNA immunoreactivity was detectable in many of the granulosa cells in the primary follicles. These results indicate that canine ovaries cryopreserved by vitrification appear to have the potential to restore endocrine function and ovulation potential.

\section{Discussion}

A bank of frozen ovarian tissues for guide dogs for the blind has the potential to contribute to 

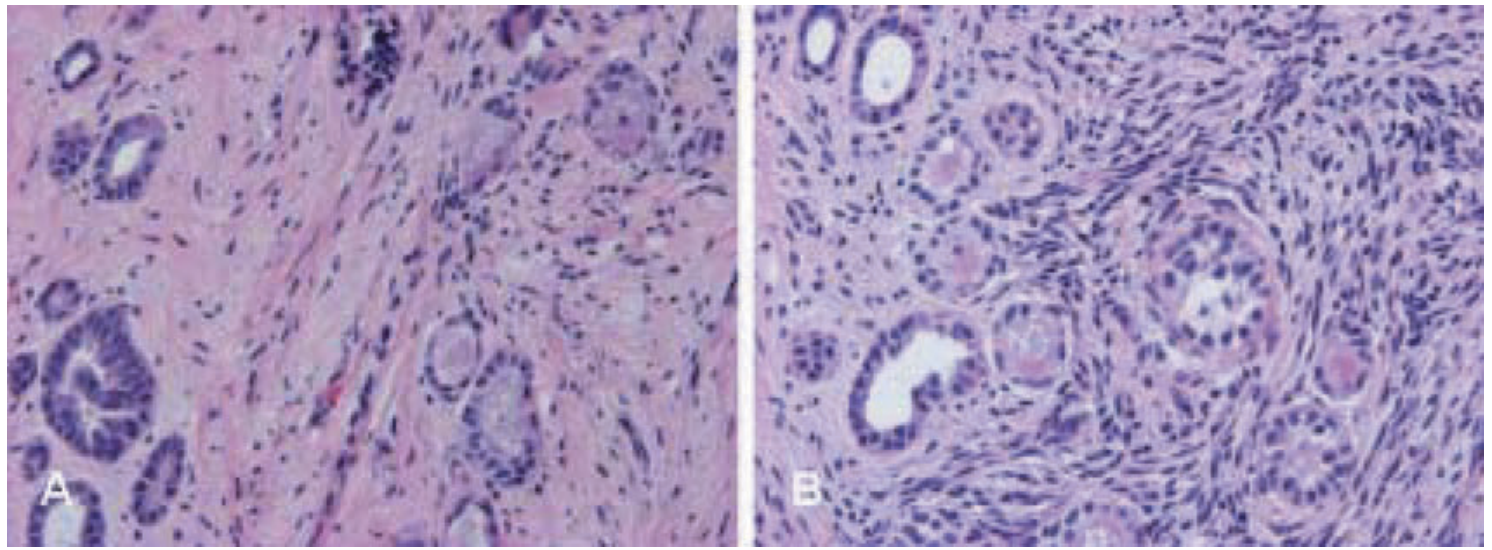

Fig. 1. Photographs showing fresh (A) and vitrified-warmed (B) canine ovarian tissues. Canine ovaries were cryopreserved by vitrification. The fresh and cryopreserved ovarian tissues are morphologically equivalent.
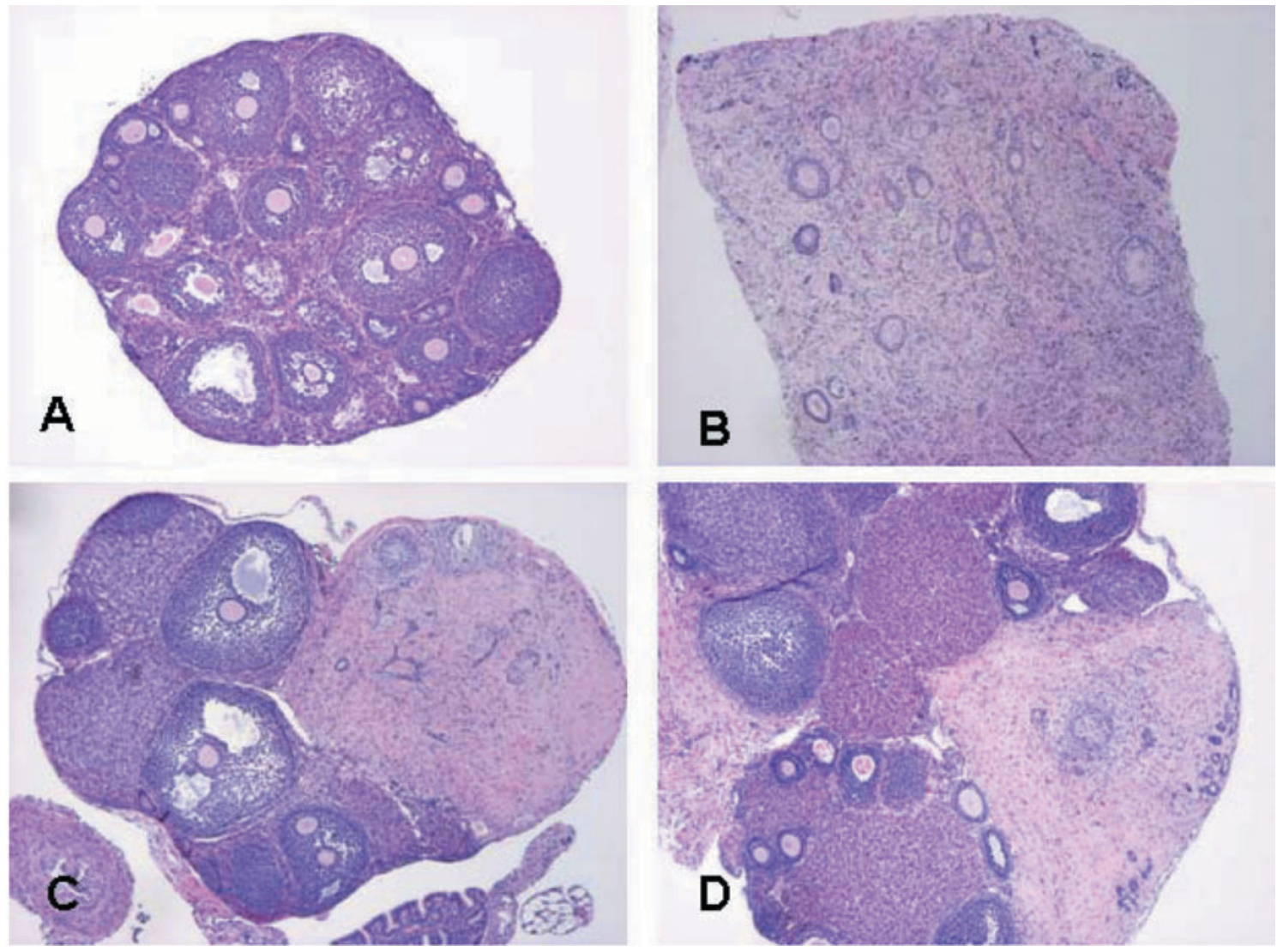

Fig. 2. Ovaries recovered from NOD-SCID mice 4 weeks after transplantation of the vitrified-warmed canine ovarian tissues into the bursa. Panels A and B show mouse and canine ovarian tissues stained with hematoxylin and eosin, respectively. Note the much deeper stain seen in the mouse ovarian tissue (A) compared with the canine ovary (B). Panels $C$ and $D$ show the mouse-canine ovary complex excised from the ovarian bursa of NOD-SCID mice. Canine ovarian grafts (pale stain) successfully adhered to mouse ovary (C and D). 

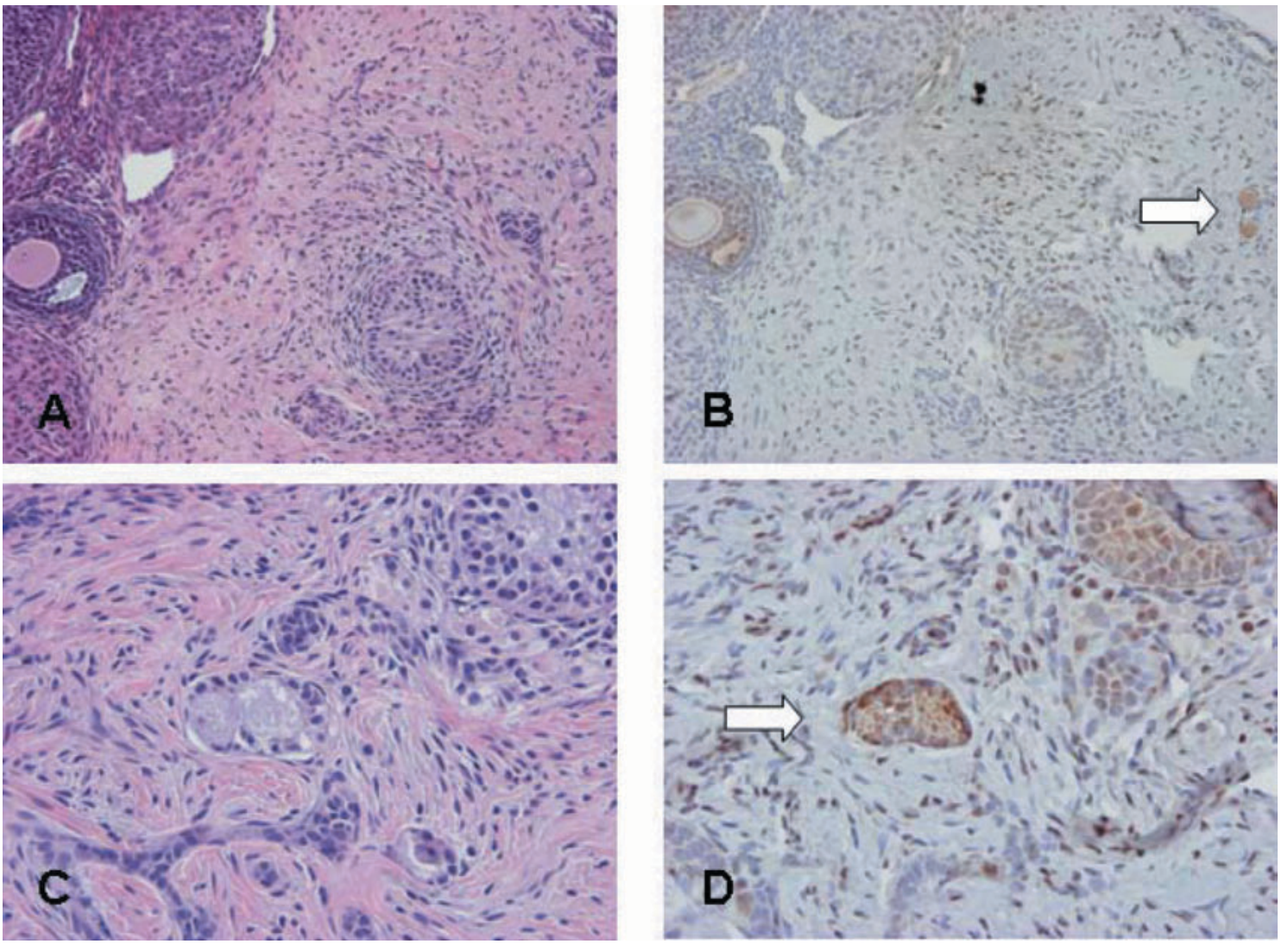

Fig. 3. Hematoxylin and eosin stain (A and C) and immunohistochemistry of PCNA (B and D) of ovaries recovered from NOD-SCID mice 4 weeks after the transplantation of the vitrified-warmed canine ovarian tissues. B) PCNA-positive oocytes of primordial follicles (white arrow). D) Primary follicles; both granulose cells and oocytes stained for PCNA (white arrow).

overcoming the shortage in the number available for patients who need them. However, several considerations need to be addressed. An important concern is the lack of an ideal protocol for the freezing and thawing processes in the case of the canine ovary, the goal of which is minimum injury to the ovarian tissues in order to restore endocrine function and ovulation potential. Since the first success in achieving live births in mice using glycerol as a cryoprotectant [10], various reports on orthotopic transplantation of cryopreserved ovaries have been published $[1,2,4,5,11-15]$. It has been considered that the removal of intracellular and intercellular water is essential for avoiding the lethal effects of the formation of large amounts of ice. Thus, the cryopreservation of ovaries by slow freezing has been employed in clinical medicine [16], as well as in laboratories [13]. Recently, however, successful orthotopic transplantation of cryopreserved ovary by vitrification has been reported in mice $[1,2]$. The technical simplicity of vitrification seems to revolutionize cryopreservation of the ovary and contributes to the goal of establishing an ovarian bank for guide dogs for the blind. In dogs, however, there has been as yet no reported attempt to cryopreserve ovarian tissues, although xenografting of fresh canine ovaries to SCID mice has been reported [17]. The data presented here indicates, for the first time, that vitrification using DAP 213 as a cryoprotectant is applicable to the cryopreservation of canine ovary suitable for banking (Fig. 1). There was no difference in terms of histological findings between the tissues of fresh ovaries and ovaries cryopreserved by vitrification (Fig. 1).

Xenogenetic transplantation of the ovarian cortex into several mouse strains carrying mutation with immunodeficiency has been employed and 
established to determine the potential of gonadal function and fertility of cryopreserved ovaries from mice [18], cats [19], marsupials [20], sheep [18], marmoset monkeys [21], elephants [22], and humans [23, 24]. Immunodeficient mice are promising research models for ovarian xenografting. Nude and SCID mouse strains are commonly used for this purpose. However, the SCID mutation is not entirely stable in blocking lymphocyte development, and $2-20 \%$ of SCID mice produce detectable levels of IgG, the so-called "leaky" mice [25]. Incomplete immunosuppression SCID mice may become a serious problem when these animals are used for long-term ovarian xenografting. In order to obviate potential rejection problems, we utilized NOD-SCID mice, a NOD strain congenic for the SCID mutation [26]. Since NOD-SCID mice are not only deficient in functional $\mathrm{B}$ and $\mathrm{T}$ lymphocytes, but also are markedly deficient in natural killer cells, macrophages, and complement activity, they appear to be suitable as an experimental model for the transplantation of canine ovarian tissues. When fresh canine ovarian tissues were transplanted into the kidney capsule of ovariectomized SCID mice, a significant shift from primordial follicles to early primary follicles was observed, but follicular development to the antral stage was not observed [17]. Our data clearly show that NOD-SCID mice are a useful tool for evaluation of the potential of vitrified-warmed canine ovaries (Figs. 2 and 3 ). The higher percentages of successful adhesion of transplanted ovaries to the mouse ovaries seem to indicate that transplantation failure might be caused by the loss of grafted tissues via escape from the slit in the bursa, rather than degeneration of the grafts after transfer. To induce antral follicle development of the grafts, exogenous gonadotropin support might be required. An important factor for successful ovarian transplantation in immunodeficient mice is the quick establishment of blood supply. Graft revascularization is crucial for the survival of ovarian follicles after xenografting. Therefore, many studies choose the subcapsular region of the kidney or the ovarian bursa as the site for transplantation. Although revascularization of the graft is known to be initiated within $48 \mathrm{~h}$ after transplantation [27], the factors responsible for stimulating angiogenesis after ovarian transplantation remain to be determined. To minimize the degree of cellular damage of the grafts, further studies are required into revascularization and protecting against damage by the reactive oxygen species generated during ischemia-reperfusion.

\section{Acknowledgements}

This study was supported by Special Coordination Funds for Promoting Science and Technology from the Ministry of Education, Culture, Sports, and Science and Technology of Japan.

\section{References}

1. Takahashi E, Miyoshi I, Nagasu T. Rescue of a transgenic mouse line by transplantation of a frozen-thawed ovary obtained postmortem. Comtemp Top Lab Anim Sci 2001; 40: 28-31.

2. Migishima F, Suzuki-Migishima R, Song S-Y, Kuramochi T, Azuma S, Nishijima M, Yokoyama M. Successful cryopreservatrion of mouse ovaries by vitrification. Biol Reprod 2003; 68: 881-887.

3. Bahdur G, Steele SJ. Ovarian tissue cryopreservation for patients. Hum Reprod 1996; 11: 22152216.

4. Donnez J, Dolmans MM, Demylle D, Jadoul P, Pirard C, Squifflet J, Martinez-Madrid B, Van Langendonckt A. Livebirth after orthotopic transplantation of cryopreserved ovarian tissue. Lancet 2004; 364: 1405-1410.
5. Meirow D, Levron J, Eldar-Geva T, Harden I, Fridman E, Zalel Y, Schiff E, Dor J. Pregnancy after transplantation of cryopreserved ovarian tissue in a patient with ovarian failure after chemotherapy. $N$ Engl J Med 2005; 353: 318-321.

6. Quinn P, Warnes GM, Kerin JF, Kirby C. Culture factors affecting the success rate of in vitro fertilization and embryo transfer. Ann NY Acad Sci 1985; 442: 195-204.

7. Whittingham DG. Embryo banks in the future of developmental genetics. Genetics 1974; 78:395-402.

8. Nakagata $\mathbf{N}$. High survival rate of unfertilized mouse oocytes after vitrification. J Reprod Fertil 1989; 87: 479-483.

9. Oktay K, Schenken RS, Nelson JF. Proliferating cell nuclear antigen marks the initiation of follicular 
growth in the rat. Biol Reprod 1995; 53: 295-301.

10. Parrot DM. The fertility of mice with orthotopic ovarian grafts derived from frozen tissue. J Reprod Fertil 1960; 1: 230-241.

11. Gosden RG, Baird DT, Wade JC, Webb R. Restoration of fertility to oophorectomized sheep by ovarian autografts stored at -196 C. Hum Reprod 1994; 9: 597-603.

12. Gunasena KT, Villines PM, Crister ES, Crister JK. Live births after autologous transplant of cryopreserved mouse ovaries. Hum Reprod 1997; 12: 101-106.

13. Sztein J, Sweet H, Farley J, Mobraaten L. Cryopreservation and orthotopic transplantation of mouse ovaries: new approach in gamete banking. Biol Reprod 1998; 58: 1071-1074.

14. Candy CJ, Wood MJ, Whittingham DG. Restoration of a normal reproductive life span after grafting of cryopreserved mouse ovaries. Hum Reprod 2000; 15: 1300-1304.

15. Shaw JM, Cox SL, Trounson AO, Jenkin G. Evaluation of the long-term function of cryopreserved ovarian grafts in the mouse, implications for human applications. Mol Cell Endocrinol 2000; 161: 103-110.

16. Gosden RG. Low temperature storage and grafting of human ovarian tissue. Mol Cell Endocrinol 2000; 163: 125-129.

17. Metcalfe SS, Shaw JM, Gunn IM. Xenografting of canine ovarian tissue to ovariectomized severe combined immunodeficient (SCID) mice. J Reprod Fertil Suppl 2001; 57: 323-329.

18. Gunasena KT, Lakey JR, Villiners PM, Crister ES, Crister JK. Allogenic and xenogenic transplantation of cryopreserved ovarian tissue to athymic mice. Biol Reprod 1997; 57: 226-231.

19. Bosch P, Hernandez-Fonseca HJ, Miller DM, Wininger JD, Massey JB, Lamb SV, Bracket BG. Development of antral follicules in cryopreserved cat ovarian tissue transplanted to immunodeficient mice. Theriogenology 2004; 61: 581-594.

20. Mattiske D, Shaw G, Shaw JM. Influence of donor age on development of gonadal tissue from pouch young of the tammar wallaby, Macropus eugenii, after cryopreservation and xenografting into mice. Reproduction 2002; 123: 143-153.

21. Candy CJ, Wood MJ, Whittingham DG. Follicular development in cryopreserved marmoset ovarian tissue after transplantation. Hum Reprod 1995; 10: 2334-2338.

22. Gunasena KT, Lakey JR, Villines PM, Bush M, Raath C, Crister ES, McGann LE, Crister JK. Antral follicles develop in xenografted cryopreserved African elephant (Loxodonta africana) ovarian tissue. Anim Reprod Sci 1998; 53: 265-275.

23. Newton H, Aubard Y, Rutherford A, Sharma V, Gosden R. Low temperature storage and grafting of human ovarian tissue. Hum Reprod 1996; 11: 14871491.

24. Gook DA, Mccully BA, Edgar DH, McBain JC. Development of antral follicles in human cryopreserved ovarian tissue following xenografting. Hum Reprod 2001; 16: 417-422.

25. Sandhu JS, Boynton E, Gorczynski R, Hozumi N. The use of SCID mice in biotechnology as a model for human disease. Crit Rev Biotechnol 1996; 16: 95118.

26. Shultz LD, Schweizer PA, Christianson SW, Gott B, Schweitzer IB, Tennent B, McKenna S, Mobraraaten L, Rajan TV, Greiner DL, Leiter EH. Multiple defects in innate and adaptive immunologic function NOD/LASZ-scid mice. J Immunol 1995; 154: 180-191.

27. Dissen GA, Lara HE, Fahrenbach WH, Costa ME, Ojeda SR. Immature rat ovaries become revascularized rapidly after autotranplantation and show gonadotropin-dependent increase in angiogenic factor gene expression. Endocrinology 1994; 134: $1146-1154$ 